\title{
Genetic continuity within, and discontinuities among, populations of leafroller moths with distinct sex-pheromones
}

\author{
CHRISTOPHER S. WHITE \& DAVID M. LAMBERT* \\ Ecology and Evolution, School of Biological Sciences, University of Auckland, Private Bag 92019, Auckland, \\ New Zealand
}

\begin{abstract}
Species belonging to two genera of leafroller moths have been shown to exhibit considerable variation in sex-pheromones. Six different pheromone types have been described, three each belonging to Planotortrix excessana and Ctenopseustis obliquana. We report here the existence of homozygous genotypes in wild-caught individuals and that no heterozygous genotypes for any of the presumptive genetic loci were recorded, despite electrophoresis of 820 individuals belonging to two pheromone types of $P$. excessana and 781 moths belonging to the two pheromone types of $C$. obliquana. This is particularly significant given that more than 500 individuals of each pair were collected from areas of sympatry. Hence these data unequivocally support the specific status of $P$. excessana pheromone type $\mathrm{A}$ and type $\mathrm{B} \& \mathrm{C}$ and $C$. obliquana type I\&III and type II. A further study of 30 presumptive genetic loci of these pheromonally-distinct cryptic species reveals considerable differences in allele frequencies at other loci and shows that within pheromonal types there is a remarkable stability in gene frequencies, with little clinal variation. The variation within pheromone types that does exist results largely from regionally-distinct populations which are either geographically isolated, or subject to a range of human disturbances. The bulk of the total genetic variation within the taxonomically-described entities is among the pheromonally-distinct species. The question of the specific status of two pheromonally-distinct but allopatric populations is addressed, and it is suggested that genetic data cannot unequivocally resolve the specific status of such groups.
\end{abstract}

Keywords: cryptic species, Ctenopseustis obliquana, isozymes, leafroller moths, pheromone strains, Planotortrix excessana.

\section{Introduction}

The biological status of New Zealand leafroller pheromone types within the existing (Dugdale, 1966) classifications Planotortrix excessana and Ctenopseustis obliquana has been under examination for several years (Foster et al., 1986, 1989, 1991; Foster \& Roelofs, 1987; Dugdale, 1990). These studies have resulted in the suggestion that the pheromone types represent distinct species on the following bases.

(1) The pheromone types possess different longrange chemical signalling systems used in reproduction (Foster et al., 1986, 1989; Foster \& Roelofs, 1987).

(2) The females of each type attract only males of the same type in mating trials (Foster et al., 1991).

*Correspondence.
(3) Some minor morphological differences have been discovered that can at least partially distinguish the types (Dugdale, 1990).

(4) Electrophoretic markers distinctive to the laboratory-reared lines of different pheromonal types have been described (Foster et al., 1991).

The above criteria have resolved two main types within each taxonomically described species; $P$. excessana type $\mathrm{A}$ and type $\mathrm{B} \& \mathrm{C}$, and $C$. obliquana type I\&III and type II. All of the above criteria coincide for these groupings with two exceptions. In the North Island (Fig. 1), C. obliquana type II cannot be separated from type I\&III on the basis of the morphological distinction, but remains consistent with type II for genetic markers, pheromone signals and mating trials (Foster et al., 1990). The second exception is for $P$. excessana types found on the Chatham Islands. These have been designated $P$. octoides by Dugdale 


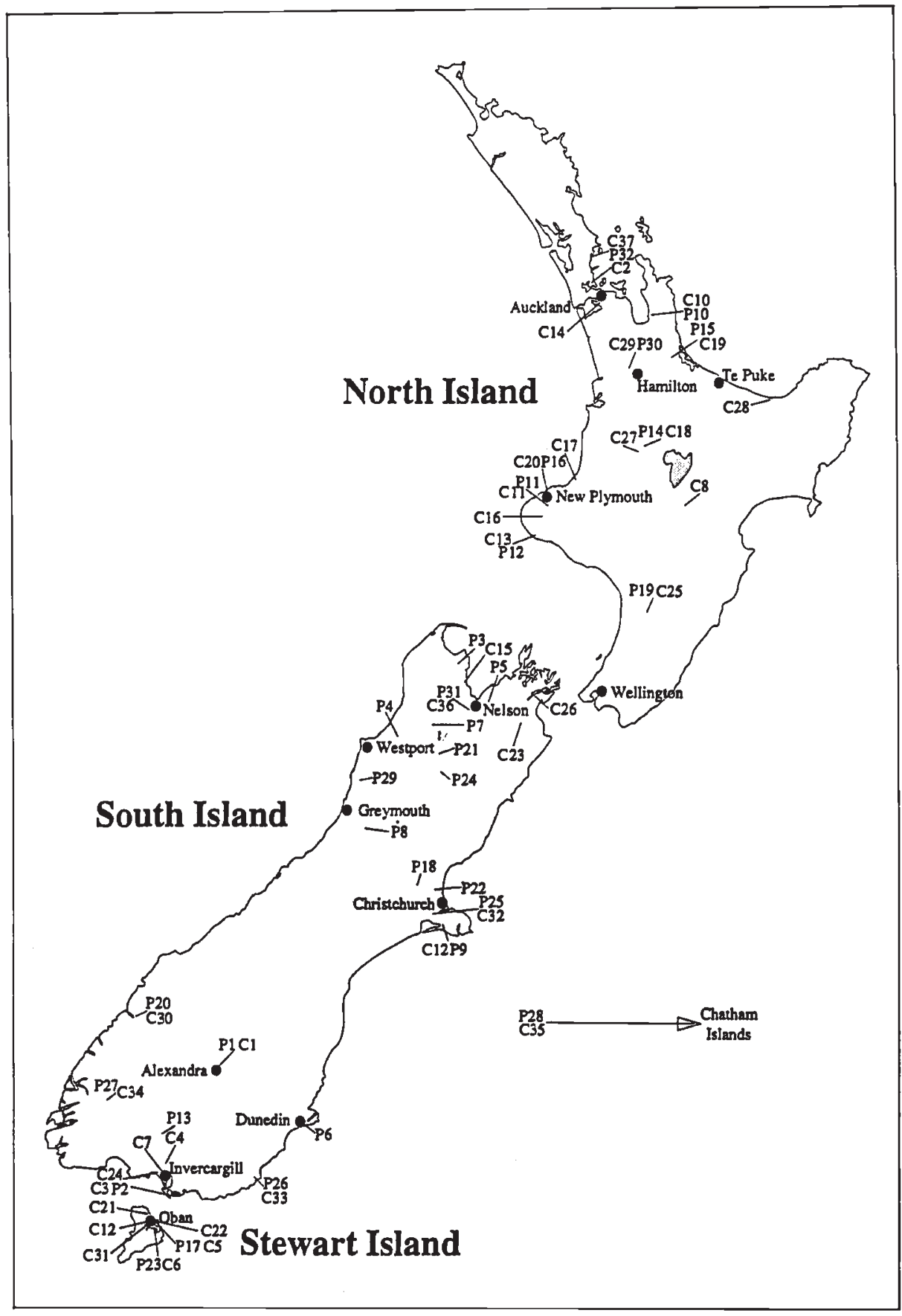

Fig. 1 Locations where Planotortrix excessana and Ctenopseustis obliquana pheromone types were sampled in this study.

(1990) on the basis of morphological characters although they have type A pheromone signalling systems. No mating trials have been conducted between $P$. octoides and mainland type A individuals.

Differences in the specific-mate recognition systems (SMRSs) (Paterson, 1985; Lambert et al., 1987; McEvey, 1992; Lambert \& Spencer, 1995) of pheromone types are of critical importance in determining their status as biological species. Thus, the pheromone signalling differences, which originally drew attention to the possibility of cryptic species within the original taxa (Galbreath et al., 1985), still provide the strongest evidence of new species. These differences are likely to be of importance given the mating and response trials conducted both in field cages and wind tunnels (Foster et al., 1991).

Despite the body of evidence available, it is difficult to confirm that the pheromone types represent species 
with unique SMRSs in their typical environment. This could be directly tested by observing the outcome of matings in sympatric populations of the respective pheromone types. If these matings defined groups concordant with the pheromone types, their specific status. would be supported. Of course markers can be used to recognize genetic discontinuities which may result from the existence of a number of species. Such an approach, while providing a great deal of information on the genetic structuring of natural populations is dependent upon finding a consistent genetic marker for each type. In the case of these leafroller moths, the $\beta$ hydroxybutyrate dehydrogenase- 3 locus has been shown to discriminate between some laboratory-reared strains of the two $P$. excessana types and the hexokinase-1 locus similarly distinguishes between some strains of the C. obliquana types (Foster et al., 1991; White \& Lambert, 1994). These electrophoretic differences were also shown, at least for the $C$. obliquana types, to produce an identifiable marker for heterozygotes between them in forced laboratory crosses. These electrophoretic markers can then be used to examine the genetic outcome of reproduction in natural populations as they may indicate the species to which any collected individuals belong.

This study aimed to investigate the genetic structure of wild populations of these leafrollers belonging to these two genera. In particular the following specific questions were of interest.

(1) Would electrophoretic markers which have been shown to discriminate among laboratory-reared strains of leafroller moths also discriminate among wild-caught individuals belonging to different pheromonal types, in that no heterozygous genotypes would be detected?

(2) Would the wider genetic structuring of the wild populations support the groupings recognized from laboratory-reared populations?

(3) Would the geographical distribution of electrophoretically-identified groupings match those of pheromonally- and morphologically-identified groupings?

The confirmation of these points would establish that the pheromone differences in SMRSs among the types result in cohesive reproductive communities in the natural habitat. In addition, the genetic structuring of populations across geographical regions and between individual sample sites can be examined to reveal the reproductive dynamics within each type and assist in the resolution of residual questions over the status of North Island C. obliquana type II and P. octoides. For the purposes of all the analyses, North Island type II are treated as part of the rest of type II and $P$. octoides is treated as $P$. excessana type A.

\section{Materials and methods}

\section{Specimens examined}

Samples of $P$. excessana and $C$. obliquana were collected from throughout mainland New Zealand and from the Chatham Islands. The sampling sites for $P$. excessana and $C$. obliquana are shown on Fig. 1 and the locations of each listed with the accompanying code in Table 1 . Individuals were collected as either eggs, larvae, pupae or adults and, whenever possible, kept alive until transported to the laboratory. Upon arrival adults were frozen immediately at $-80^{\circ} \mathrm{C}$, while earlier stages were kept in culture until they reached the adult form and were then frozen in the same manner.

\section{Electrophoresis procedures}

In all analyses 'Cellogel' electrophoresis medium was used and buffers and strains were as detailed by Richardson et al. (1986). First, all samples were analysed electrophoretically for either the $\beta$-hydroxybutyrate dehydrogenase or the hexokinase enzyme systems, depending on the taxonomic grouping to which they belonged. Secondly, individuals from sampling sites that produced near to, or more than 20

Table 1 Sample sites, numbers of moths and numbers of each pheromone type of Planotortrix excessana and Ctenopsensis obliquana recorded in this study

\begin{tabular}{clrrr}
\hline $\begin{array}{l}\text { Sample } \\
\text { code }\end{array}$ & Sample site & $\begin{array}{r}\text { Number } \\
\text { analysed }\end{array}$ & $\begin{array}{r}\text { Number } \\
\text { of A }\end{array}$ & $\begin{array}{r}\text { Number } \\
\text { of B\&C }\end{array}$ \\
\hline P1 & Alexandra & 62 & 28 & 34 \\
P2 & Bluff Hill & 40 & 18 & 22 \\
P3 & Caanan & 49 & 19 & 30 \\
P4 & Dublin Tce & 3 & 0 & 3 \\
P5 & Dun Mountain & 12 & 7 & 5 \\
P6 & Dunedin & 2 & 1 & 1 \\
P7 & Hope River & 4 & 3 & 1 \\
P8 & Jacksons & 7 & 5 & 2 \\
P9 & Kaituna & 4 & 0 & 4 \\
P10 & Kauranga Valley & 4 & 4 & 0 \\
P11 & Lake Mangamahoe & 1 & 0 & 1 \\
P12 & Manaia & 5 & 2 & 3 \\
P13 & Moss Bush & 5 & 1 & 4 \\
P14 & Mt Pureora & 7 & 3 & 4 \\
P15 & Mt Te Aroha & 9 & 2 & 7 \\
P16 & New Plymouth & 14 & 4 & 10 \\
P17 & Oban & 97 & 0 & 97 \\
P18 & Okuku & 8 & 0 & 8 \\
P19 & Palmerston North & 56 & 33 & 23 \\
P20 & Sandfly Point & 3 & 2 & 1 \\
P21 & Shenandoah & 38 & 18 & 20 \\
& & & &
\end{tabular}


Table 1 Continued

\begin{tabular}{llrrr}
\hline $\begin{array}{l}\text { Sample } \\
\text { code }\end{array}$ & Sample site & $\begin{array}{r}\text { Number } \\
\text { analysed }\end{array}$ & $\begin{array}{r}\text { Number } \\
\text { of A }\end{array}$ & $\begin{array}{c}\text { Number } \\
\text { of B\&C }\end{array}$ \\
\hline P22 & St Albans & 3 & 2 & 1 \\
P23 & Stewart Island & 3 & 0 & 3 \\
P24 & Sylvia Flats & 8 & 2 & 6 \\
P25 & Tai Tapu & 49 & 29 & 20 \\
P26 & Tautuku & 6 & 2 & 4 \\
P27 & Te Anua & 11 & 0 & 11 \\
P28 & Te Matarae & 98 & 98 & 0 \\
P29 & Truman Track & 54 & 20 & 34 \\
P30 & Waikato & 117 & 73 & 44 \\
P31 & Wairoa Gorge & 38 & 17 & 21 \\
P32 & Wenderholm & 3 & 3 & 0
\end{tabular}

\begin{tabular}{|c|c|c|c|c|}
\hline $\begin{array}{l}\text { Sample } \\
\text { code }\end{array}$ & Sample size & $\begin{array}{l}\text { Number } \\
\text { analysed }\end{array}$ & $\begin{array}{c}\text { Number } \\
\text { of I\&III }\end{array}$ & $\begin{array}{c}\text { Number } \\
\text { of II }\end{array}$ \\
\hline $\mathrm{C} 1$ & Alexandra & 11 & 11 & 0 \\
\hline $\mathrm{C} 2$ & Birkenhead & 4 & 4 & 0 \\
\hline C3 & Bluff Hill & 49 & 28 & 21 \\
\hline $\mathrm{C} 4$ & Forest Hill & 8 & 5 & 3 \\
\hline $\mathrm{C} 5$ & Fred's Camp & 5 & 4 & 1 \\
\hline C6 & Horseshoe Bay & 42 & 25 & 17 \\
\hline $\mathrm{C} 7$ & Invercargill & 2 & 2 & 0 \\
\hline $\mathrm{C} 8$ & Kaimanawas & 26 & 24 & 2 \\
\hline $\mathrm{C} 9$ & Kaipipi Creek & 1 & 1 & 0 \\
\hline $\mathrm{C} 10$ & Kauranga Valley & 12 & 11 & 1 \\
\hline C11 & Lake Mangamahoe & 12 & 9 & 3 \\
\hline $\mathrm{C} 12$ & Little River & 8 & 5 & 3 \\
\hline $\mathrm{C} 13$ & Manaia & 10 & 8 & 2 \\
\hline $\mathrm{C} 14$ & Manurewa & 22 & 19 & 3 \\
\hline C15 & Mariri & 2 & 2 & 0 \\
\hline C16 & Mt Egmont & 7 & 7 & 0 \\
\hline $\mathrm{C} 17$ & Mt Messenger & 1 & 1 & 0 \\
\hline C18 & Mt Pureora & 3 & 3 & 0 \\
\hline C19 & Mt Te Aroha & 4 & 4 & 0 \\
\hline $\mathrm{C} 20$ & New Plymouth & 9 & 5 & 4 \\
\hline $\mathrm{C} 21$ & Oban & 167 & 97 & 70 \\
\hline $\mathrm{C} 22$ & Observation Rock & 2 & 0 & 2 \\
\hline $\mathrm{C} 23$ & Onamalutu & 51 & 18 & 33 \\
\hline $\mathrm{C} 24$ & Otatara & 2 & 0 & 2 \\
\hline $\mathrm{C} 25$ & Palmerston North & 11 & 11 & 0 \\
\hline $\mathrm{C} 26$ & Pelorus Sound & 2 & 1 & 1 \\
\hline $\mathrm{C} 27$ & Pureora & 2 & 2 & 0 \\
\hline $\mathrm{C} 28$ & Raroa & 3 & 3 & 0 \\
\hline $\mathrm{C} 29$ & Rukuhia & 83 & 50 & 33 \\
\hline C30 & Sandfly Point & 3 & 1 & 2 \\
\hline C31 & Stewart Island & 51 & 23 & 28 \\
\hline C32 & Tai Tapu & 5 & 5 & 0 \\
\hline C33 & Tautuku & 7 & 5 & 2 \\
\hline C34 & Te Anau & 57 & 20 & 37 \\
\hline $\mathrm{C} 35$ & Te Matarae & 81 & 0 & 81 \\
\hline C36 & Wairoa Gorge & 13 & 5 & 8 \\
\hline C37 & Wenderholm & 18 & 18 & 0 \\
\hline
\end{tabular}

Sample codes P1-P32 refer to $P$. excessana; codes C1-C37 refer to C. obliquana. individuals of either type were analysed for all loci which were polymorphic in laboratory populations, i.e. a total of 26 polymorphic and four monomorphic loci. A maximum of 50 individuals of any one type were analysed from each site. The 22 enzyme systems screened were: aconitate hydratase (Acon; EC 4.2.1.3), adenosine deaminase (Ada; 3.5.4.4), adenylate kinase (Ak; 2.7.4.3), aldehyde oxidase (Ao; 1.2.3.1), esterase (Est; 3.1.1.1), fumarate hydratase (Fum; 4.2.1.2), aspartate aminotransferase (Got; 2.6.1.1), glucose-6phosphate dehydrogenase (G6pd; 1.1.1.49), glycerol3-phosphate dehydrogenase $(\alpha \mathrm{Gpd} ; 1.1 .1 .8)$, glucose-phosphate isomerase $(\mathrm{Gpi}$; 5.3.1.9), glutathione reductase (Gsr; 1.6.4.2), glucuronidase (Gus; 3.2.1.31), $\beta$-hydroxybutyrate dehydrogenase (Hbdh; 1.1.1.30), hexokinase ( $\mathrm{Hk} ; 2.7 .1 .1)$, isocitrate dehydrogenase (Iḍh; 1.1.1.42), malate dehydrogenase (Mdh; 1.1.1.37), malic enzyme (Me; 1.1.1.40), mannose phosphate isomerase (Mpi; 5.3.1.8), phosphoglycerate mutase (Pgam; 2.7.5.3), phosphoglucomutase (Pgm; 5.4.2.2), xanthine dehydrogenase (Xdh; 1.1 .1 .204$)$ and xanthine oxidase $(\mathrm{Xo} ; 1.2 .3 .2)$.

\section{Results}

To confirm the discrimination of the two loci for wildcaught individuals, a total of 820 moths of $P$. excessana were analysed for the Hbdh-3 locus. Of these, 396 were homozygous for a fast electrophoretic variant and were therefore apparently of type A. The remaining 424 individuals were homozygous for a slower variant at the same locus and were consequently regarded as belonging to type $B \& C$. The sample locations and the numbers analysed and their allocation to the two types are shown in Table 1 and Fig. 1. For the C. obliquana samples a total of 796 individuals were analysed for the $H k-1$ locus. Of this sample, 437 moths were homozygous for a slow electromorph, indicating they were of type I\&III, and a further 359 individuals were homozygous for a faster variant and therefore were assigned to type II. The locations and numbers analysed for these samples are also shown in Table 1 and Fig. 1, along with the allocation into each type at each site. No heterozygous genotypes were recorded within any of the pheromone types, despite screening over 500 individuals for each pair of congeneric species from localities where the types were sympatric. In addition, all individuals that were successfully scored could be allocated to the four electrophoretic groups identified in laboratory populations, i.e. no new electromorphs for the marker loci were discovered in the wildcollected individuals.

The populations that had sufficient numbers for analysis for the remainder of the 22 enzyme systems listed earlier are shown in Table 2. The distributions of 
Table 2 Locations and sample sizes of wild populations of leafroller moths which were analysed for 22 enzyme systems

\begin{tabular}{|c|c|c|c|c|c|}
\hline $\begin{array}{l}\text { Sample } \\
\text { code }\end{array}$ & Sample site & Region & $\begin{array}{l}\text { Taxonomic } \\
\text { group }\end{array}$ & $\begin{array}{l}\text { Pheromone } \\
\text { type }\end{array}$ & $\begin{array}{l}\text { Number } \\
\text { analysed }\end{array}$ \\
\hline $\mathrm{C} 3$ & Bluff Hill & SSI & C. obliquana & $\begin{array}{l}\text { I\&III } \\
\text { II }\end{array}$ & $\begin{array}{l}28 \\
21\end{array}$ \\
\hline C6 & Horseshoe Bay & STI & C. obliquana & $\begin{array}{c}\text { I\&III } \\
\text { II }\end{array}$ & $\begin{array}{l}25 \\
17\end{array}$ \\
\hline $\mathrm{C} 8$ & Kaimanawas & NI & C. obliquana & I\&III & 24 \\
\hline $\mathrm{C} 14$ & Manurewa & NI & C. obliquana & I\&III & 19 \\
\hline $\mathrm{C} 21$ & Oban & STI & C. obliquana & $\begin{array}{c}\text { I\&III } \\
\text { II }\end{array}$ & $\begin{array}{l}50 \\
50\end{array}$ \\
\hline $\mathrm{C} 23$ & Onamalutu & NSI & C. obliquana & $\begin{array}{c}\text { I\&III } \\
\text { II }\end{array}$ & $\begin{array}{l}18 \\
33\end{array}$ \\
\hline C29 & Rukuhia & NI & C. obliquana & $\begin{array}{l}\text { I\&III } \\
\text { II }\end{array}$ & $\begin{array}{l}50 \\
33\end{array}$ \\
\hline C31 & Stewart Island & STI & C. obliquana & $\begin{array}{l}\text { I\&III } \\
\text { II }\end{array}$ & $\begin{array}{l}23 \\
28\end{array}$ \\
\hline C34 & Te Anau & SSI & C. obliquana & $\begin{array}{c}\text { I\&III } \\
\text { II }\end{array}$ & $\begin{array}{l}20 \\
37\end{array}$ \\
\hline C35 & Te Matarae & $\mathrm{CHI}$ & C. obliquana & II & 45 \\
\hline C37 & Wenderholm & NI & C. obliquana & I\&III & 18 \\
\hline $\mathrm{P} 1$ & Alexandra & SSI & P. excessana & $\begin{array}{c}\mathrm{A} \\
\mathrm{B} \& \mathrm{C}\end{array}$ & $\begin{array}{l}28 \\
34\end{array}$ \\
\hline $\mathrm{P} 2$ & Bluff Hill & SSI & P. excessana & $\begin{array}{c}A \\
B \& C\end{array}$ & $\begin{array}{l}18 \\
22\end{array}$ \\
\hline P3 & Caanan & NSI & P. excessana & $\begin{array}{c}\text { A } \\
B \& C\end{array}$ & $\begin{array}{l}19 \\
30\end{array}$ \\
\hline P17 & Oban & STI & P. excessana & $B \& C$ & 50 \\
\hline P19 & Palmerston North & NI & P. excessana & $\begin{array}{c}\mathrm{A} \\
\mathrm{B} \& \mathrm{C}\end{array}$ & $\begin{array}{l}33 \\
23\end{array}$ \\
\hline $\mathrm{P} 21$ & Shenandoah & NSI & P. excessana & $\begin{array}{c}A \\
B \& C\end{array}$ & $\begin{array}{l}18 \\
20\end{array}$ \\
\hline $\mathrm{P} 25$ & Tai Tapu & NSI & P. excessana & $\begin{array}{c}A \\
B \& C\end{array}$ & $\begin{array}{l}29 \\
20\end{array}$ \\
\hline P28 & Te Matarae & $\mathrm{CHI}$ & P. excessana & A & 36 \\
\hline P29 & Truman Track & NSI & P. excessana & $\begin{array}{c}A \\
B \& C\end{array}$ & $\begin{array}{l}20 \\
34\end{array}$ \\
\hline P30 & Waikato & NI & P. excessana & $\begin{array}{c}A \\
B \& C\end{array}$ & $\begin{array}{l}50 \\
44\end{array}$ \\
\hline P31 & Wairoa Gorge & NSI & P. excessana & $\begin{array}{c}\text { A } \\
B \& C\end{array}$ & $\begin{array}{l}17 \\
21\end{array}$ \\
\hline
\end{tabular}

NI, North Island; NSI, north of the South Island above and including Chirstchurch; SSI, south of theSouth Island below Christchurch; STI, Stewart Island; CHI, Chatham Islands.

$P$. excessana types were largely sympatric with two notable exceptions; P17 was type B\&C only and P28 was type A only (Table 1).

The $C$. obliquana type II had a patchy distribution in the North Island but was found at all other sites except C1. Only type II was found at site C35. Type I\&III was found in the North Island, South Island and Stewart Island.

\section{Analyses of genetic equilibrium}

The electromorph frequencies for all loci for all species are presented in Tables 3-6. Hardy-Weinberg analyses revealed a consistent pattern of no significant deviation from equilibrium for almost all the populations, including the Chatham Island population of $P$. excessana type A. The relatively small sample sizes of many of the 
Table 3 Electromorph frequencies in wild populations of Planotortrix excessana type A

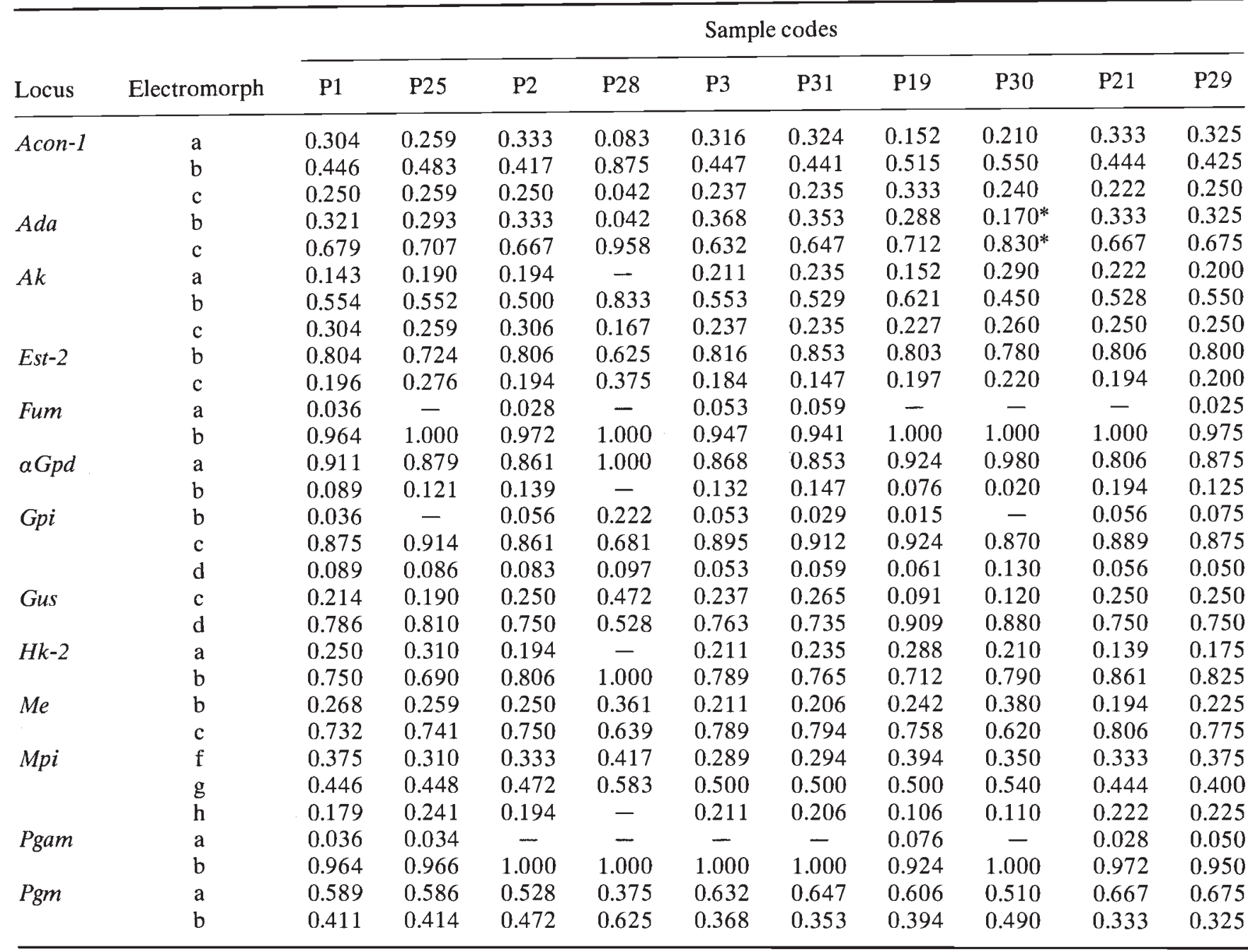

*Significant deviation from H.-W. (sample codes as in Table 2).

The following electromorphs were fixed: Acon-2 a, Ao a, Est-1 a, Got-1 a, Got-2 a, G6pd a, Gsr a, Hbdh-1 a, Hbdh-2 a, Hbdh-3 b, Hk-1 a, Idh-1 a, Idh-2 b, Mdh-1 a, Mdh-2 b, Xdh a, Xo a.

populations, combined with the presence of three electromorphs for several loci, made these tests relatively insensitive in many cases. However, even quite large samples, such as those from Stewart Island, showed no significant deviation from the expected equilibrium frequencies.

The exceptions to the above generality were in two sets of populations and the deviations from equilibrium are shown in the frequency Tables 3-6. The first set were populations that were not geographically widely separated from others, but found near areas of human activity. For $P$. excessana type $\mathrm{A}$ and both $C$. obliquana types, these populations showed deviation from Hardy-Weinberg at one or more loci. This was particularly notable for the $C$. obliquana types for which these populations were also divergent in every other genetic measure. The second set of populations are represented by the Chatham Island $C$. obliquana type II population which showed significant deviations from equilibrium at four loci. This was not paralleled by any similar deviation in the $P$. excessana type A population from the Chathams.

The source of the deviation from equilibrium was the same in every case. All deviating loci in the populations concerned showed an excess of homozygotes. However, in most cases the disequilibrium was also associated with a difference in the frequencies of the electromorphs for the locus in question, suggesting that the data reflected some kind of active process, rather than an epiphenomenon of the electromorph scoring technique. 
Table 4 Electromorph frequencies in wild populations of Planotortrix excessana type B\&C

\begin{tabular}{|c|c|c|c|c|c|c|c|c|c|c|c|}
\hline \multirow[b]{2}{*}{ Locus } & \multirow[b]{2}{*}{ Electromorph } & \multicolumn{10}{|c|}{ Sample codes } \\
\hline & & P1 & $\mathrm{P} 25$ & P2 & P3 & P31 & P19 & P17 & P30 & $\mathrm{P} 21$ & P29 \\
\hline \multirow[t]{3}{*}{ Acon-1 } & a & 0.162 & 0.100 & 0.159 & 0.167 & 0.190 & 0.217 & 0.190 & 0.261 & 0.225 & 0.235 \\
\hline & b & 0.485 & 0.450 & 0.477 & 0.517 & 0.524 & 0.435 & 0.530 & 0.386 & 0.475 & 0.471 \\
\hline & c & 0.353 & 0.450 & 0.364 & 0.317 & 0.286 & 0.348 & 0.280 & 0.352 & 0.300 & 0.294 \\
\hline \multirow[t]{2}{*}{ Ada } & b & 0.574 & 0.550 & 0.591 & 0.600 & 0.571 & 0.500 & 0.630 & 0.545 & 0.675 & 0.647 \\
\hline & c & 0.426 & 0.450 & 0.409 & 0.400 & 0.429 & 0.500 & 0.370 & 0.455 & 0.325 & 0.353 \\
\hline \multirow[t]{3}{*}{$A k$} & a & 0.162 & 0.100 & 0.159 & 0.167 & 0.190 & 0.217 & 0.190 & $0.261^{*}$ & 0.225 & 0.250 \\
\hline & b & 0.485 & 0.450 & 0.477 & 0.517 & 0.524 & 0.435 & 0.530 & $0.386^{*}$ & 0.700 & 0.691 \\
\hline & c & 0.353 & 0.450 & 0.364 & 0.317 & 0.286 & 0.348 & 0.280 & $0.352^{*}$ & 0.050 & 0.059 \\
\hline \multirow[t]{2}{*}{$\alpha G p d$} & a & 0.985 & 0.975 & 1.000 & 0.983 & 1.000 & 1.000 & 0.960 & 1.000 & 0.975 & 0.985 \\
\hline & $\mathrm{b}$ & 0.015 & 0.025 & - & 0.017 & - & - & 0.040 & - & 0.025 & 0.015 \\
\hline \multirow[t]{2}{*}{$G p i$} & b & 0.279 & 0.250 & 0.295 & 0.267 & 0.286 & 0.217 & 0.310 & 0.193 & 0.300 & 0.294 \\
\hline & c & 0.721 & 0.750 & 0.705 & 0.733 & 0.714 & 0.783 & 0.690 & 0.807 & 0.700 & 0.706 \\
\hline \multirow[t]{2}{*}{ Gus } & c & 0.853 & 0.825 & 0.909 & 0.917 & 0.905 & 0.804 & 0.880 & 0.795 & 0.925 & 0.926 \\
\hline & d & 0.147 & 0.175 & 0.091 & 0.083 & 0.095 & 0.196 & 0.120 & 0.205 & 0.075 & 0.074 \\
\hline \multirow[t]{2}{*}{$H k=2$} & a & 0.279 & 0.250 & 0.318 & 0.350 & 0.310 & 0.283 & 0.310 & 0.250 & 0.325 & 0.309 \\
\hline & b & 0.721 & 0.750 & 0.682 & 0.650 & 0.690 & 0.717 & 0.690 & 0.750 & 0.675 & 0.691 \\
\hline \multirow[t]{2}{*}{$M d h-2$} & a & 0.897 & 0.800 & 0.864 & 0.917 & 0.905 & 0.870 & 0.930 & 0.795 & 0.925 & 0.912 \\
\hline & b & 0.103 & 0.200 & 0.136 & 0.083 & 0.095 & 0.130 & 0.070 & 0.205 & 0.075 & 0.088 \\
\hline \multirow[t]{2}{*}{$M e$} & b & 0.647 & 0.675 & 0.705 & 0.700 & 0.690 & 0.587 & 0.680 & 0.602 & 0.675 & 0.691 \\
\hline & c & 0.353 & 0.325 & 0.295 & 0.300 & 0.310 & 0.413 & 0.320 & 0.398 & 0.325 & 0.309 \\
\hline \multirow[t]{2}{*}{$M p i$} & f & 0.235 & 0.200 & 0.295 & 0.250 & 0.286 & 0.196 & 0.280 & 0.250 & 0.300 & 0.338 \\
\hline & $\mathrm{g}$ & 0.765 & 0.800 & 0.705 & 0.750 & 0.714 & 0.804 & 0.720 & 0.750 & 0.700 & 0.662 \\
\hline \multirow[t]{2}{*}{ Pgam } & a & 0.176 & 0.200 & 0.114 & 0.100 & 0.119 & 0.217 & 0.130 & 0.080 & 0.100 & 0.147 \\
\hline & b & 0.824 & 0.800 & 0.886 & 0.900 & 0.881 & 0.783 & 0.870 & 0.920 & 0.900 & 0.853 \\
\hline \multirow[t]{2}{*}{$P g m$} & a & 0.221 & 0.225 & 0.227 & 0.150 & 0.190 & 0.261 & 0.110 & 0.295 & 0.100 & 0.147 \\
\hline & $b$ & 0.779 & 0.775 & 0.773 & 0.850 & 0.810 & 0.739 & 0.890 & 0.705 & 0.900 & 0.853 \\
\hline
\end{tabular}

*Significant deviation from H.-W. (sample codes as in Table 2).

The following electromorphs were fixed: Acon-2 a, Ao a, Est-1 a, Est-2 b, Fum b, Got-1 a, Got-2 a, G6pd a, Gsr a, Hbdh-1 a, $H b d h-2$ a, $H b d h-3$ a, $H k-1$ a, Idh-I a, Idh-2 b, Mdh-1 a, Xdh a, Xo a.

\section{Genetic heterogeneity}

To examine genetic structuring, hierarchical heterogeneity $\chi^{2}$ analyses were performed for all cases where there was more than one population of any type within a region. The populations were divided into regions as shown in Table 7. There was no detailed biogeographical rationale for the regional divisions made, other than a correlation with the major spatial and geographical discontinuities between the groups of populations sampled. To examine heterogeneity amongst all populations of each type, heterogeneity analyses were also performed across all the regions. The results are shown only for the comparison of loci for which significant heterogeneity was recorded.

For the $P$. excessana no significant heterogeneity was recorded amongst the populations of either $P$. excessana type within the regions described (Table 7). The single exception was the Pgam locus for which there was a significant deviation for both types in the
North Island region. Examination of the electromorph frequency data suggests this arose mainly from differences between the P30 and P19 populations at this locus.

For the analysis across all regions, the type A populations showed significant heterogeneity for 9 out of 13 loci (Table 8). From the frequency data for the most heterogeneous loci ( $G p i$ and $G u s$ ) the main differences are found between the Chatham Island (P28) population and all other populations. The results for the type $\mathrm{B} \& \mathrm{C}$ populations tend to support this. No significant heterogeneity was observed at any locus for this type.

The results of the heterogeneity analyses for the $C$. obliquana showed no significant heterogeneity amongst the populations within the South Island and Stewart Island regions for either type I\&III or type II. However, for the North Island region, the type I\&III populations showed significant heterogeneity at 14 out of $16 \mathrm{loci}$, with 10 of these showing highly significant $(P<0.01)$ heterogeneity (Table 7$)$. This high level of 
Tahle 5 Electromorph frequencies in wild populations of Ctenopseustis obliquana type I\&III

\begin{tabular}{|c|c|c|c|c|c|c|c|c|c|c|c|}
\hline \multirow[b]{2}{*}{ Locus } & \multirow[b]{2}{*}{ Electromorph } & \multicolumn{10}{|c|}{ Sample codes } \\
\hline & & C37 & $\mathrm{C} 14$ & $\mathrm{C} 8$ & $\mathrm{C} 3$ & $\mathrm{C} 23$ & C6 & $\mathrm{C} 21$ & C31 & $\mathrm{C} 34$ & $\mathrm{C} 29$ \\
\hline \multirow[t]{3}{*}{ Acon-1 } & a & 0.079 & 0.056 & 0.104 & 0.089 & 0.111 & 0.080 & 0.110 & 0.043 & 0.075 & 0.030 \\
\hline & b & 0.842 & 0.944 & 0.833 & 0.804 & 0.833 & 0.760 & 0.790 & 0.804 & 0.825 & 0.920 \\
\hline & c & 0.079 & - & 0.063 & 0.107 & 0.056 & 0.160 & 0.100 & 0.152 & 0.100 & 0.050 \\
\hline \multirow[t]{3}{*}{ Ada } & a & 0.632 & $0.417^{*}$ & 0.583 & 0.679 & 0.583 & 0.720 & 0.740 & 0.761 & 0.575 & $0.370^{*}$ \\
\hline & c & 0.053 & - & 0.063 & - & 0.056 & 0.020 & 0.010 & - & 0.050 & - \\
\hline & d & 0.316 & 0.583* & 0.354 & 0.321 & 0.361 & 0.260 & 0.250 & 0.239 & 0.375 & $0.630^{*}$ \\
\hline \multirow[t]{2}{*}{ Ao } & a & 0.553 & 0.333 & 0.583 & 0.625 & 0.583 & 0.660 & 0.610 & 0.696 & 0.625 & $0.790^{*}$ \\
\hline & $\mathrm{b}$ & 0.447 & 0.667 & 0.417 & 0.375 & 0.417 & 0.340 & 0.390 & 0.304 & 0.375 & $0.210^{*}$ \\
\hline \multirow[t]{2}{*}{ Est-2 } & $\mathrm{a}$ & 0.684 & $0.889^{*}$ & 0.708 & 0.625 & 0.667 & 0.600 & 0.630 & 0.652 & 0.600 & 0.930 \\
\hline & $\mathrm{b}$ & 0.316 & $0.111^{*}$ & 0.292 & 0.375 & 0.333 & 0.400 & 0.370 & 0.348 & 0.400 & 0.070 \\
\hline \multirow[t]{2}{*}{ Fum } & $\mathrm{b}$ & 0.079 & - & 0.083 & 0.161 & 0.111 & 0.180 & 0.130 & 0.130 & 0.175 & - \\
\hline & c & 0.921 & 1.000 & 0.917 & 0.839 & 0.889 & 0.820 & 0.870 & 0.870 & 0.825 & 1.000 \\
\hline \multirow[t]{3}{*}{$\alpha G p d$} & $\mathrm{~b}$ & 0.026 & - & 0.021 & 0.089 & 0.056 & 0.080 & 0.100 & 0.109 & 0.075 & - \\
\hline & c & 0.868 & $0.667^{*}$ & 0.875 & 0.804 & 0.750 & 0.800 & 0.790 & 0.783 & 0.825 & 0.960 \\
\hline & d & 0.105 & $0.333^{*}$ & 0.104 & 0.107 & 0.194 & 0.120 & 0.110 & 0.109 & 0.100 & 0.040 \\
\hline \multirow[t]{3}{*}{ Gpi } & a & 0.079 & - & 0.104 & 0.089 & 0.083 & 0.080 & 0.080 & 0.065 & 0.100 & - \\
\hline & $\mathrm{b}$ & 0.842 & 1.000 & 0.771 & 0.750 & 0.833 & 0.740 & 0.780 & 0.826 & 0.775 & 1.000 \\
\hline & c & 0.079 & - & 0.125 & 0.161 & 0.083 & 0.180 & 0.140 & 0.109 & 0.125 & - \\
\hline \multirow[t]{2}{*}{ Gsr } & $\mathrm{a}$ & 0.289 & 0.083 & 0.250 & 0.214 & 0.250 & 0.300 & 0.310 & 0.283 & 0.300 & $0.400^{*}$ \\
\hline & $\mathrm{b}$ & 0.711 & 0.917 & 0.750 & 0.786 & 0.750 & 0.700 & 0.690 & 0.717 & 0.700 & $0.600^{*}$ \\
\hline \multirow[t]{3}{*}{ Gus } & a & 0.447 & $0.611^{*}$ & 0.438 & 0.375 & 0.417 & 0.380 & 0.350 & 0.370 & 0.375 & 0.390 \\
\hline & b & 0.342 & $0.389^{*}$ & 0.354 & 0.411 & 0.333 & 0.380 & 0.400 & 0.413 & 0.425 & 0.540 \\
\hline & c & 0.211 & - & 0.208 & 0.214 & 0.250 & 0.240 & 0.250 & 0.217 & 0.200 & 0.070 \\
\hline \multirow[t]{2}{*}{$H b d h-2$} & a & 0.105 & 0.306 & 0.104 & 0.196 & 0.194 & 0.200 & 0.250 & 0.217 & 0.225 & 0.020 \\
\hline & b & 0.895 & 0.694 & 0.896 & 0.804 & 0.806 & 0.800 & 0.750 & 0.783 & 0.775 & 0.980 \\
\hline \multirow[t]{2}{*}{$H k-2$} & $\mathrm{~b}$ & 0.447 & $0.694^{*}$ & 0.354 & 0.411 & 0.417 & 0.340 & 0.340 & 0.413 & 0.400 & 0.090 \\
\hline & c & 0.553 & $0.306^{*}$ & 0.646 & 0.589 & 0.583 & 0.660 & 0.660 & 0.587 & 0.600 & 0.910 \\
\hline \multirow[t]{2}{*}{$I d h-2$} & a & 0.553 & $0.333^{*}$ & 0.542 & 0.500 & 0.528 & 0.520 & 0.480 & 0.500 & 0.450 & 0.440 \\
\hline & b & 0.447 & $0.667^{*}$ & 0.458 & 0.500 & 0.472 & 0.480 & 0.520 & 0.500 & 0.550 & 0.560 \\
\hline \multirow[t]{2}{*}{$M e$} & b & 0.868 & 0.944 & 0.896 & 0.821 & 0.861 & 0.800 & 0.790 & 0.826 & 0.800 & 0.740 \\
\hline & c & 0.132 & 0.056 & 0.104 & 0.179 & 0.139 & 0.200 & 0.210 & 0.174 & 0.200 & 0.260 \\
\hline \multirow[t]{5}{*}{$M p i$} & a & 0.053 & - & 0.042 & 0.089 & 0.056 & 0.040 & 0.080 & 0.043 & 0.075 & - \\
\hline & b & 0.447 & 0.750 & 0.417 & 0.375 & 0.472 & 0.440 & 0.370 & 0.413 & 0.450 & $0.530^{*}$ \\
\hline & c & 0.395 & 0.222 & 0.396 & 0.411 & 0.333 & 0.360 & 0.370 & 0.413 & 0.375 & $0.420^{*}$ \\
\hline & d & 0.053 & 0.028 & 0.083 & 0.125 & 0.083 & 0.080 & 0.120 & 0.087 & 0.050 & $0.050^{*}$ \\
\hline & e & 0.053 & - & 0.063 & - & 0.056 & 0.080 & 0.060 & 0.043 & 0.050 & - \\
\hline \multirow[t]{3}{*}{$P g m$} & c & 0.105 & 0.056 & 0.104 & 0.089 & 0.111 & 0.160 & 0.120 & 0.174 & 0.100 & - \\
\hline & d & 0.658 & 0.528 & 0.688 & 0.625 & 0.639 & 0.520 & 0.540 & 0.522 & 0.600 & 0.720 \\
\hline & $\mathrm{e}$ & 0.237 & 0.417 & 0.208 & 0.286 & 0.250 & 0.320 & 0.340 & 0.304 & 0.300 & 0.280 \\
\hline \multirow[t]{2}{*}{$X o$} & $\mathrm{a}$ & 0.053 & - & 0.083 & - & 0.056 & - & - & - & - & - \\
\hline & b & 0.947 & 1.000 & 0.917 & 1.000 & 0.944 & 1.000 & 1.000 & 1.000 & 1.000 & 1.000 \\
\hline
\end{tabular}

*Significant deviation from H.-W. (sample codes as for Table 2).

The following electromorphs were fixed: Acon-2 a, $A k$ c, Est-1 a, Got-1 a, Got-2 b, G6pd b, Hbdh-1 a, Hbdh-3 a, Hk-1 b, Idh-1 b, $M d h-1$ a, $M d h-2$ c, Pgam b, Xdh b.

structuring among North Island populations apparently results from the differences of the $\mathrm{C} 14$ and C29 populations from the $\mathrm{C} 8$ and $\mathrm{C} 37$ populations.

Comparisons across all populations revealed significant heterogeneity at 10 out of 16 loci for type I\&III populations and 12 out of 13 loci for type II popula- tions (Table 8). The patterns of difference amongst type I\&II populations essentially reflect those found amongst the North Island populations, in that most populations throughout the country differ only slightly, with the exception of the $\mathrm{C} 14$ and $\mathrm{C} 29$ populations. These two populations are not only quite different 
Table 6 Electromorph frequencies in wild populations of Ctenopseustis obliquana type II

\begin{tabular}{|c|c|c|c|c|c|c|c|c|c|}
\hline \multirow[b]{2}{*}{ Locus } & \multirow[b]{2}{*}{ Electromorph } & \multicolumn{8}{|c|}{ Sample codes } \\
\hline & & $\mathrm{C} 3$ & C35 & $\mathrm{C} 23$ & C6 & $\mathrm{C} 21$ & C31 & $\mathrm{C} 34$ & $\mathrm{C} 29$ \\
\hline \multirow[t]{2}{*}{ Acon-1 } & a & 0.190 & 0.044 & 0.182 & 0.206 & 0.200 & 0.214 & 0.162 & - \\
\hline & b & 0.810 & 0.956 & 0.818 & 0.794 & 0.800 & 0.786 & 0.838 & 1.000 \\
\hline \multirow[t]{3}{*}{$A d a$} & $\mathrm{a}$ & 0.357 & 0.511 & 0.394 & 0.412 & 0.400 & 0.429 & 0.365 & - \\
\hline & c & 0.119 & - & 0.106 & 0.088 & 0.110 & 0.071 & 0.149 & 0.500 \\
\hline & d & 0.524 & 0.489 & 0.500 & 0.500 & 0.490 & 0.500 & 0.486 & 0.500 \\
\hline \multirow[t]{2}{*}{ Ao } & a & 0.214 & $0.511^{*}$ & 0.258 & 0.324 & 0.290 & 0.321 & 0.216 & - \\
\hline & b & 0.786 & $0.489^{*}$ & 0.742 & 0.676 & 0.710 & 0.679 & 0.784 & 1.000 \\
\hline \multirow[t]{2}{*}{ Est-2 } & $\mathrm{a}$ & 0.929 & 1.000 & 0.909 & 0.912 & 0.870 & 0.911 & 0.919 & $0.848^{*}$ \\
\hline & b & 0.071 & - & 0.091 & 0.088 & 0.130 & 0.089 & 0.081 & $0.152 *$ \\
\hline \multirow[t]{2}{*}{$G p i$} & $\mathrm{a}$ & 0.476 & $0.256^{*}$ & 0.455 & 0.412 & 0.400 & 0.375 & 0.432 & $0.621^{*}$ \\
\hline & b & 0.524 & $0.744^{*}$ & 0.545 & 0.588 & 0.600 & 0.625 & 0.568 & $0.379^{*}$ \\
\hline \multirow[t]{2}{*}{ Gsr } & $\mathrm{b}$ & 0.048 & - & 0.045 & 0.088 & 0.120 & 0.089 & 0.068 & 0.182 \\
\hline & c & 0.952 & 1.000 & 0.955 & 0.912 & 0.880 & 0.911 & 0.932 & 0.818 \\
\hline \multirow[t]{3}{*}{ Gus } & a & 0.833 & 0.922 & 0.833 & 0.853 & 0.840 & 0.875 & 0.824 & $0.758^{*}$ \\
\hline & $\mathrm{b}$ & 0.143 & 0.078 & 0.152 & 0.088 & 0.110 & 0.071 & 0.162 & $0.242^{*}$ \\
\hline & c & 0.024 & - & 0.015 & 0.059 & 0.050 & 0.054 & 0.014 & - \\
\hline \multirow[t]{2}{*}{$H b d h-2$} & $\mathrm{a}$ & 0.071 & $0.367^{*}$ & 0.061 & 0.118 & 0.160 & 0.089 & 0.054 & - \\
\hline & b & 0.929 & $0.633^{*}$ & 0.939 & 0.882 & 0.840 & 0.911 & 0.946 & 1.000 \\
\hline \multirow[t]{2}{*}{$H k \cdot 2$} & b & 0.214 & - & 0.182 & 0.235 & 0.210 & 0.268 & 0.176 & 0.242 \\
\hline & c & 0.786 & 1.000 & 0.818 & 0.765 & 0.790 & 0.732 & 0.824 & 0.758 \\
\hline \multirow[t]{2}{*}{$M p i$} & b & 0.310 & 0.089 & 0.303 & 0.235 & 0.230 & 0.214 & 0.297 & 0.364 \\
\hline & c & 0.690 & 0.911 & 0.697 & 0.765 & 0.770 & 0.786 & 0.703 & 0.636 \\
\hline \multirow[t]{2}{*}{ Pgam } & $\mathrm{a}$ & 0.024 & - & 0.045 & - & - & - & 0.054 & - \\
\hline & b & 0.976 & 1.000 & 0.955 & 1.000 & 1.000 & 1.000 & 0.946 & 1.000 \\
\hline \multirow[t]{3}{*}{$P g m$} & c & 0.119 & - & 0.167 & 0.118 & 0.110 & 0.089 & 0.135 & - \\
\hline & d & 0.762 & 1.000 & 0.727 & 0.735 & 0.700 & 0.732 & 0.730 & 0.909 \\
\hline & $\mathrm{e}$ & 0.119 & - & 0.106 & 0.147 & 0.190 & 0.179 & 0.135 & 0.091 \\
\hline \multirow[t]{2}{*}{$X o$} & $\mathrm{a}$ & 0.119 & $0.289^{*}$ & 0.091 & 0.088 & 0.070 & 0.054 & 0.122 & $0.182^{*}$ \\
\hline & b & 0.881 & $0.711^{*}$ & 0.909 & 0.912 & 0.930 & 0.946 & 0.878 & $0.818^{*}$ \\
\hline
\end{tabular}

*Significant deviation from H.-W. (sample codes as for Table 2).

The following electromorphs were found to be fixed: Acon-2 a, Ak c, Est-1 a, Fum c, Got-1a, Got-2 b, G6pd b, $\alpha$ Gpd c, Hbdh-1 a, $H b d h-3$ a, $H k-1$ c, Idh-1 b, Idh-2 a, $M d h-1$ a, $M d h-2$ c, $M e$ a, $X d h$ b.

from the other populations at the Ada locus, but they also differ from all other populations and considerably from each other for the Hk-2 locus. The type II patterns are not dissimilar. Amongst the South Island and Stewart Island populations there is minor variation in electromorph frequencies at the Ada and Ao loci. However, the single North Island and Chatham Island populations are very different, both from the remaining populations and each other.

\section{F-statistics}

Analyses were carried out at five levels: site (population), region, species (pheromone type), genus (a cryptic complex) and total. The results clearly showed that there was low differentiation $\left(F_{\mathrm{ST}}<0.05\right)$ at most loci and moderate differentiation $\left(0.05<F_{\mathrm{ST}}<0.15\right)$ at a few, for comparisons between populations within regions or species, or between regions within species. However, there is great or very great differentiation $\left(0.25<F_{\mathrm{ST}}\right)$ at most loci for populations, regions or species within genera. Grouping populations into pheromone types removes by far the most heterozygosity amongst subpopulations and explains a high proportion of the total genetic variance within the Dugdale (1966) taxa.

\section{Discussion}

\section{Biological status of pheromone types}

The first objective of this genetic analysis was to determine if the genetic distinctness which identified different pheromone types in the laboratory-reared moths 
Table $7 \quad \chi^{2}$ heterogeneity analysis for populations of Planotortrix excessana type A and type B\&C and Ctenopseustis obliquana type I\&III from three geographical regions of New Zealand

\begin{tabular}{|c|c|c|c|c|c|c|c|c|c|}
\hline \multirow[b]{2}{*}{ Locus } & \multicolumn{3}{|c|}{ North Island } & \multicolumn{3}{|c|}{ North South Island } & \multicolumn{3}{|c|}{ South South Island } \\
\hline & $\chi^{2}$ & d.f. & $P$ & $\chi^{2}$ & d.f. & $P$ & $\chi^{2}$ & d.f. & $P$ \\
\hline \multicolumn{10}{|c|}{$P$. excessana type A } \\
\hline Acon-1 & 2.068 & 2 & 0.35556 & 0.953 & 8 & 0.99853 & 0.106 & 2 & 0.94828 \\
\hline Ada & 3.253 & 1 & 0.07130 & 0.698 & 4 & 0.95158 & 0.014 & 1 & 0.90538 \\
\hline$A k$ & 5.668 & 2 & 0.05879 & 0.376 & 8 & 0.99996 & 0.476 & 2 & 0.78819 \\
\hline Est-2 & 0.127 & 1 & 0.72184 & 2.567 & 4 & 0.63272 & 0.001 & 1 & 0.98128 \\
\hline Fum & 0.000 & 0 & 1.00000 & 5.344 & 4 & 0.25382 & 0.044 & 1 & 0.83431 \\
\hline$\alpha G p d$ & 3.060 & 1 & 0.08023 & 1.171 & 4 & 0.88290 & 0.557 & 1 & 0.45567 \\
\hline Gpi & 3.516 & 2 & 0.17240 & 4.881 & 8 & 0.77020 & 0.212 & 2 & 0.89933 \\
\hline Gus & 0.348 & 1 & 0.55522 & 0.927 & 4 & 0.92065 & 0.159 & 1 & 0.69039 \\
\hline$H k-2$ & 1.318 & 1 & 0.25087 & 4.615 & 4 & 0.32916 & 0.384 & 1 & 0.53550 \\
\hline$M e$ & 3.429 & 1 & 0.06407 & 0.686 & 4 & 0.95305 & 0.036 & 1 & 0.84901 \\
\hline$M p i$ & 0.336 & 2 & 0.84537 & 1.354 & 8 & 0.99487 & 0.168 & 2 & 0.91949 \\
\hline Pgam & 7.811 & 1 & $0.00519^{* *}$ & 3.183 & 4 & 0.52767 & 1.314 & 1 & 0.25162 \\
\hline Pgm & 1.481 & 1 & 0.22357 & 1.051 & 4 & 0.90192 & 0.337 & 1 & 0.56136 \\
\hline \multicolumn{10}{|c|}{ P. excessana type $\mathrm{B} \& \mathrm{C}$} \\
\hline Acon-1 & 0.415 & 2 & 0.81277 & 5.699 & 8 & 0.68091 & 0.013 & 2 & 0.99337 \\
\hline Ada & 0.251 & 1 & 0.61668 & 1.996 & 4 & 0.73656 & 0.033 & 1 & 0.85557 \\
\hline$A k$ & 0.283 & 2 & 0.86820 & 1.499 & 8 & 0.99272 & 0.582 & 2 & 0.74759 \\
\hline$\alpha G p d$ & 0.000 & 0 & 1.00000 & 1.103 & 4 & 0.89372 & 0.653 & 1 & 0.41908 \\
\hline Gpi & 0.110 & 1 & 0.74010 & 0.385 & 4 & 0.98370 & 0.034 & 1 & 0.85437 \\
\hline Gus & 0.015 & 1 & 0.90301 & 3.587 & 4 & 0.46482 & 0.770 & 1 & 0.38020 \\
\hline$H k-2$ & 0.166 & 1 & 0.68328 & 1.156 & 4 & 0.88532 & 0.193 & 1 & 0.66026 \\
\hline$M d h-2$ & 1.129 & 1 & 0.28809 & 4.808 & 4 & 0.30757 & 0.291 & 1 & 0.58967 \\
\hline$M e$ & 0.029 & 1 & 0.86374 & 0.108 & 4 & 0.99860 & 0.399 & 1 & 0.52757 \\
\hline$M p i$ & 0.502 & 1 & 0.47872 & 2.768 & 4 & 0.59741 & 0.504 & 1 & 0.47780 \\
\hline Pgam & 5.182 & 1 & $0.02282^{*}$ & 2.704 & 4 & 0.60850 & 0.819 & 1 & 0.36541 \\
\hline Pgm & 0.178 & 1 & 0.67323 & 2.748 & 4 & 0.60076 & 0.007 & 1 & 0.93387 \\
\hline \multicolumn{10}{|c|}{ C. obliquana type I\&III } \\
\hline Acon-1 & 6.473 & 6 & 0.37236 & 0.082 & 2 & 0.95995 & 2.934 & 4 & 0.56896 \\
\hline Ada & 22.099 & 6 & $0.00116^{* *}$ & 3.389 & 2 & 0.18372 & 1.036 & 4 & 0.90431 \\
\hline Ao & 26.017 & 3 & $0.00001^{* * *}$ & 0.000 & 1 & 1.00000 & 1.093 & 2 & 0.57906 \\
\hline Est-2 & 19.012 & 3 & $0.00027^{* * *}$ & 0.062 & 1 & 0.80403 & 0.284 & 2 & 0.86750 \\
\hline Fum & 11.444 & 3 & $0.00955^{* *}$ & 0.034 & 1 & 0.85309 & 0.756 & 2 & 0.68513 \\
\hline$\alpha G p d$ & 26.139 & 6 & $0.00021^{* * *}$ & 0.082 & 2 & 0.95995 & 0.269 & 4 & 0.99172 \\
\hline Gpi & 30.714 & 6 & $0.00003^{* * *}$ & 0.252 & 2 & 0.88169 & 1.192 & 4 & 0.87935 \\
\hline Gsr & 13.463 & 3 & $0.00374 * *$ & 0.914 & 1 & 0.33898 & 0.113 & 2 & 0.94522 \\
\hline Gus & 19.822 & 6 & $0.00298^{* *}$ & 0.034 & 2 & 0.98300 & 0.299 & 4 & 0.98986 \\
\hline$H b d h-2$ & 24.226 & 3 & $0.00002^{* * *}$ & 0.115 & 1 & 0.73398 & 0.522 & 2 & 0.77039 \\
\hline$H k-2$ & 51.620 & 3 & $0.00000^{* * *}$ & 0.011 & 1 & 0.91604 & 0.818 & 2 & 0.66428 \\
\hline$I d h-2$ & 5.068 & 3 & 0.16692 & 0.234 & 1 & 0.62876 & 0.220 & 2 & 0.89601 \\
\hline$M e$ & 10.892 & 3 & $0.01232^{*}$ & 0.070 & 1 & 0.79085 & 0.258 & 2 & 0.87903 \\
\hline$M p i$ & 23.527 & 12 & $0.02357^{*}$ & 4.655 & 4 & 0.32452 & 3.018 & 8 & 0.93322 \\
\hline Pgm & 15.282 & 6 & $0.01817^{*}$ & 0.069 & 2 & 0.96627 & 0.945 & 4 & 0.91808 \\
\hline Xo & 10.512 & 3 & $0.01468^{*}$ & 0.000 & 0 & 1.00000 & 0.000 & 0 & 1.00000 \\
\hline
\end{tabular}

${ }^{*} P \leqslant 0.05,{ }^{* *} P \leqslant 0.01,{ }^{* * *} P<0.001$. 
Table $8 \chi^{2}$ heterogeneity analysis for populations of Ctenopseustis obliquana and Planotortrix excessana pheromone types from different geographical regions

C. obliquana type II from two regions

\begin{tabular}{|c|c|c|c|c|c|c|}
\hline \multirow[b]{2}{*}{ Locus } & \multicolumn{3}{|c|}{ South of the South Island } & \multicolumn{3}{|c|}{ Stewart Island } \\
\hline & $\chi^{2}$ & d.f. & $P$ & $\chi^{2}$ & d.f. & $P$ \\
\hline Acon-1 & 0.151 & 1 & 0.69803 & 0.045 & 2 & 0.97775 \\
\hline$A d a$ & 0.249 & 2 & 0.88282 & 0.663 & 4 & 0.95577 \\
\hline Ao & 0.001 & 1 & 0.98060 & 0.232 & 2 & 0.89033 \\
\hline Est -2 & 0.035 & 1 & 0.85186 & 0.815 & 2 & 0.66545 \\
\hline Gpi-1 & 0.207 & 1 & 0.64879 & 0.144 & 2 & 0.93045 \\
\hline Gsr & 0.188 & 1 & 0.66456 & 0.487 & 2 & 0.78386 \\
\hline Gus & 0.232 & 2 & 0.89060 & 0.673 & 4 & 0.95466 \\
\hline$H b d h-2$ & 0.143 & 1 & 0.70568 & 1.641 & 2 & 0.44015 \\
\hline$H k i-2$ & 0.260 & 1 & 0.61020 & 0.678 & 2 & 0.71231 \\
\hline$M p i$ & 0.019 & 1 & 0.89034 & 0.070 & 2 & 0.96576 \\
\hline Pgam & 0.594 & 1 & 0.44080 & 0.000 & 0 & 1.00000 \\
\hline Pgm & 0.145 & 2 & 0.93022 & 0.542 & 4 & 0.96929 \\
\hline Xo & 0.002 & 1 & 0.96736 & 0.407 & 2 & 0.81584 \\
\hline
\end{tabular}

$P$. excessana types from throughout New Zealand

\begin{tabular}{|c|c|c|c|c|c|c|c|}
\hline \multicolumn{4}{|c|}{ P. excessana type A } & \multicolumn{4}{|c|}{ P. excessana type $\mathrm{B} \& \mathrm{C}$} \\
\hline Locus & $\chi^{2}$ & d.f. & $P$ & Locus & $\chi^{2}$ & d.f. & $P$ \\
\hline Acon-1 & 51.778 & 18 & $0.00004^{* * *}$ & Acon-1 & 11.962 & 18 & 0.84921 \\
\hline Ada & 30.770 & 9 & $0.00032^{* * *}$ & Ada & 5.461 & 9 & 0.79244 \\
\hline$A k$ & 37.090 & 18 & $0.00510^{* *}$ & $A k$ & 9.084 & 18 & 0.95776 \\
\hline Est -2 & 12.563 & 9 & 0.18340 & $\alpha G p d$ & 8.080 & 9 & 0.52609 \\
\hline Fum & 15.488 & 9 & 0.07838 & $G p i$ & 4.798 & 9 & 0.85153 \\
\hline$\alpha G p d$ & 23.402 & 9 & $0.00535^{* *}$ & Gus & 12.304 & 9 & 0.19673 \\
\hline$G p i$ & 57.223 & 18 & $0.00001^{* * *}$ & $H k$ & 2.711 & 9 & 0.97467 \\
\hline Gus & 39.462 & 9 & $0.00001^{* * *}$ & $M d h-2$ & 13.735 & 9 & 0.13205 \\
\hline$H k-2$ & 27.870 & 9 & $0.00100^{* * *}$ & $M e$ & 3.991 & 9 & 0.91202 \\
\hline$M e$ & 11.853 & 9 & 0.22174 & $M p i$ & 5.023 & 9 & 0.83231 \\
\hline$M p i$ & 26.388 & 18 & 0.09122 & Pgam & 8.899 & 9 & 0.44668 \\
\hline Pgam & 17.284 & 9 & $0.04444 *$ & Pgm & 16.600 & 9 & 0.05536 \\
\hline Pgm & 17.746 & 9 & $0.03824^{*}$ & & & & \\
\hline
\end{tabular}

C. obliquana types from throughout New Zealand

C. obliquana type I\&III

\begin{tabular}{|c|c|c|c|c|c|c|c|}
\hline Locus & $\chi^{2}$ & d.f. & $P$ & Locus & $\chi^{2}$ & d.f. & $P$ \\
\hline Acon-1 & 19.704 & 18 & 0.34971 & Acon-1 & 26.164 & 7 & $0.00047^{* * *}$ \\
\hline$A d a$ & 63.927 & 18 & $0.00000^{* * *}$ & $A d a$ & 108.389 & 14 & $0.00000^{* * *}$ \\
\hline Ao & 27.587 & 9 & $0.00112^{* *}$ & $A o$ & 53.292 & 7 & $0.00000^{* * *}$ \\
\hline Est-2 & 40.736 & 9 & $0.00001^{* * *}$ & Est-2 & 14.522 & 7 & $0.04264^{*}$ \\
\hline Fum & 25.318 & 9 & $0.00264^{* *}$ & $G p i$ & 22.531 & 7 & $0.00206^{* *}$ \\
\hline$\alpha G p d$ & 42.626 & 18 & $0.00090^{* * *}$ & Gsr & 21.327 & 7 & $0.00332^{* *}$ \\
\hline$G p i$ & 40.197 & 18 & $0.00196^{* *}$ & Gus & 23.306 & 14 & 0.05547 \\
\hline Gsr & 15.876 & 9 & 0.06953 & $H b d h-2$ & 63.668 & 7 & $0.00000^{* * *}$ \\
\hline Gus & 29.592 & 18 & $0.04161^{*}$ & $H k-2$ & 26.298 & 7 & $0.00045^{* * *}$ \\
\hline$H b d h-2$ & 29.981 & 9 & $0.00044^{* * *}$ & $M p i$ & 20.473 & 7 & $0.00463^{* *}$ \\
\hline$H k-2$ & 53.057 & 9 & $0.00000^{* * *}$ & Pgam & 17.101 & 7 & $0.01676^{*}$ \\
\hline$I d h-2$ & 6.226 & 9 & 0.71706 & Pgm & 47.794 & 14 & $0.00001^{* * *}$ \\
\hline$M e$ & 11.760 & 9 & 0.22716 & Xo & 28.322 & 7 & $0.00019^{* * *}$ \\
\hline$M p i$ & 44.766 & 36 & 0.14994 & & & & \\
\hline Pgm & 26.001 & 18 & 0.09974 & & & & \\
\hline$X o$ & 30.232 & 9 & $0.00040^{* * *}$ & & & & \\
\hline
\end{tabular}

${ }^{*} P \leqslant 0.05,{ }^{* *} P \leqslant 0.01,{ }^{* * *} P \leqslant 0.001$. 
was consistent among wild populations. Based on the results, many populations were a mixture of congeneric pheromone types. The complete absence of any heterozygotes in these populations at the $\mathrm{Hbdh}-3$ locus for $P$. excessana pheromone types and at the $H k-1$ locus for $C$. obliquana pheromone types confirms that these types do indeed represent biological species in nature. This consequently supports the suggestion that they are defined by differences in their respective SMRSs, in which long-range pheromone signalling forms an important part.

\section{Population structuring}

The recognition concept recognizes two consequences of differences in SMRS for the genetic structuring of populations which are a mixture of two 'cryptic' species. The first is a high level of discontinuity over the population as a whole and the second is relative genetic continuity within each 'cryptic' species. All the major genetic structuring noted in the wild populations of leafrollers pivots on the division of the generic groupings into their composite pheromone types. Some additional structuring is evident at lower levels but is of a lesser scale and more restricted nature. The general patterns in the frequency distribution of electromorphs observed are also generally consistent with that recorded for the laboratory-reared populations.

There was a high degree of genetic stability in gene frequencies within each pheromone type across considerable distances which suggests that these moths have reproductively continuous distributions. This may be because of the ability of the moths to move reasonable distances during their life history or because of other processes, such as wind or repeated human introductions which could move individuals or egg batches across greater distances. There is no suggestion of discrete geographical subdivision within the pheromone types, or even differences across broad geographical regions.

Together, the two properties of heterogeneity across and relative homogeneity within pheromone types would have confirmed the biological species status of these groups even in the absence of a distinct genetic marker. However, in such a case the pheromone typing of individuals would have been necessary prior to genetic analysis. There was some location-specific differentiation of leafroller populations where no significant geographical discontinuity existed. These locations (P30, C29 and C37) were in highly modified areas with regular chemical control programmes and frequent habitat modification with cultivation practices. Such conditions could produce local population crashes, extinctions and habitat effects which could produce genetic differentiation of the type seen. All other collections were for populations in areas that were relatively undisturbed.

\section{Biological status of some of the populations}

The biological status of some of the populations was less clear. Dugdale (1990) expressed doubt over whether North Island $C$. obliquana type II can be considered part of the same taxonomic entity as the rest of the type II populations based on differences in the forewing to costal fold length ratio. The type II population from North Island certainly did prove genetically differentiated from the South and Stewart Island populations. However, this level of differentiation did not approach that observed among the pheromone types. In addition, a similar level of differentiation was recorded between the Chatham Island (C35) type II population and the remaining populations, although there is no suggestion that this represents a distinct biological or taxonomic type.

Dugdale (1990) also considered that this difference between North Island and South Island type II was insufficient to justify differentiating them taxonomically without additonal supporting evidence. Currently, such a separation is not supported by pheromone differences, mating trials or absolute genetic differences. Thus type II appears to be homogeneous from a biological perspective.

Dugdale (1990) has differentiated $P$. excessana type A into $P$. octoides on the Chatham Islands and P. octo elsewhere based on relatively minor morphological differences. The Chatham Island population shows some genetic differentiation from the mainland populations but at a much lower level than seen between the type $A$ and $B \& C$ pheromone types. The differentiation observed would not be unexpected for a population of a species spatially, and as a consequence almost certainly reproductively separated from its parent population for some time. Thus a thorough comparison of the pheromone composition of the mainland and Chatham populations and mating trials between them would be required to resolve the question whether $P$. octoides is a separate biological entity.

The key issue in using the genetic data in this way is the focus on the biological implications of the data in terms of what they tell us about reproduction and mate recognition. Other authors have also used such data sets in this way (Green et al., 1990; Comparini \& Biasiolo, 1991; Eber et al., 1991). Other studies which draw taxonomic conclusions from the degree of genetic differentiation between groups often attempt to use such data as a measure of divergence and thus, they argue, of species status. Steck (1991), for example, compared the $F_{\mathrm{ST}}$ values in Anastrepha and Rhagoletis to argue for the existence of cryptic species in the 
former genus. This is essentially a taxonomic approach which identifies species on the basis of some arbitrary level of difference rather than as discrete cohesive biological entities.

This study illustrates the value of genetic data for the identification of biological species when correlated with other biological information, in this case pheromone differences of importance in mate recognition. Distinct genetic markers are most useful, but patterns of discontinuities and continuities can also provide invaluable information on the status of groups within sympatric populations.

\section{Acknowledgements}

This research was made possible by grants from the Auckland University Research Committee to the authors. Much assistance was also provided by the DSIR Entomology Division, Mt Albert. In particular, Dr Steven Foster helped a great deal by discussing the work in detail and by providing resources. Dr John Dugdale also helped by discussing a range of issues concerned with the taxonomy of leafroller moths. We thank the DSIR for providing a postgraduate scholarship to CSW. This contribution represents publication number 52 from the Evolutionary Genetics Laboratory, University of Auckland.

\section{References}

COMPARINI, A. AND BIASIOLO, A. 1991. Genetic discrimination of the Italian bee, Apis mellifera ligustica versus Carniolan bee, Apis mellifera carnice by allozyme variability analysis. Biochem. Syst. Ecol., 19, 189-194.

DUGDale, J. s. 1966. A new genus for the "elusive Tortrix" (Lepidoptera: Tortricidae: Tortricinae). N. Z. J. Sci., 9, 391-398.

Dugdale, J. s. 1990. Reassessment of Ctenopseustis Meyrick and Planotortrix Dugdale with descriptions of two new genera (Lepidoptera: Tortricidae). N. Z. J. Zool., 17, 437-465.

EBER, S., STURM, P. AND BRANDL, R. 1991. Genetic and morphological variation among biotypes of Tephritis bardanae. Biochem. Syst. Ecol., 19, 549-557.
FOSTER, S. P., CLEARWATER, J. R. AND MUGGLESTON, S. J. 1989. Intra-specific variation of two components in the sex pheromone gland of a Planotortrix excessana sibling species. J. Chem. Ecol., 15, 457-465.

FOSTER, S. P., CLEARWATER, J. R., MUGGLESTON, S. J., DUGDALE, J. S. AND ROELOFS, W. L. 1986. Probable sibling species complexes within two described New Zealand leafroller moths. Naturwissenschaften, 73, 156-158.

FOSTER, S. P., CLEARWATER, J. R., MUGGLESTON, S. J. AND SHAW, P. W. 1990. Sex pheromone of a Planotortrix excessana sibling species and reinvestigation of related species. J. Chem. Ecol., 16, 2461-2474.

FOSTER, S. P., DUGDALE, J. S. AND WHite, c. S. 1991. Sex pheromones and the status of greenheaded and brownheaded leafroller moths in New Zealand. N. Z. J. Zool., 18, 63-74.

FOSTER, S. P. AND ROELOFS, W. L. 1987. Sex pheromone differences in populations of the brownheaded leafroller, Ctenopseustis obliquana. J. Chem. Ecol., 13, 623-629.

GALBREATH, R. A., BENN, M. H., YOUNG, H. AND HOLT, V. A. 1985. Sex pheromone components in New Zealand greenheaded leafroller Planotortrix excessana (Lepidoptera: Tortricidae). Z. Naturforsch., 40C, 266-271.

GREEN, C. A., GASS, R. F., MUNSTERMANN, L. E. AND BAIMAI, v. 1990. Population-genetic evidence for two species of Anopheles minimus in Thailand. Med. Vet. Entomol., 4, 25-34.

LAMBERT, D. M., MICHAUX, B. AND WHITE, C. S. 1987. Are species self-defining? Syst. Zool., 36, 196-205.

LAMBERT, D. M. AND SPENCER, H. G. 1995. Speciation and the Recognition Concept: Theory and Application. Johns Hopkins University Press, Baltimore, MD.

McEVEY, s. 1992. The Recognition Concept of Species. Johns Hopkins University Press, Baltimore, MD.

PATERSON, H. E. 1985. The recognition concept of species. In: Vrba, E. S. (ed.) Species and Speciation, pp. 21-29. Transvaal Museum Monograph No. 4, Transvaal Museum, Pretoria.

RICHARDSON, B. J., BAVERSTOCK, P. J. AND ADAMS, M. 1986. Allozyme Electrophoresis: A Handbook for Animal Systematics and Population Studies. Academic Press, Sydney.

STECK, G. J. 1991. Bichemical systematics and population genetic structure of Anastrepha fraterculus and related species (Diptera: Tephritidae). Ann. Entomol. Soc. Am., 84, 10-28.

WHITE, C. S. AND LAMBERT, D. M. 1994. Genetic differences among pheromonally distinct New Zealand leafroller moths. Biochem. Syst. Ecol., 22, 329-339. 